\title{
A Marca Como Elemento Cultural - A Moda Ecológica de Flavia Aranha ${ }^{1}$
}

\author{
La Marca Como Elemento Cultural - La Moda Ecológica de Flavia \\ Aranha
}

The Brand as a Cultural Element - Flavia Aranha Eco-Fashion

\author{
Lana de Araújo Gomides ${ }^{2}$
}

\begin{abstract}
Resumo
Atualmente as marcas podem ser reconhecidas como um elemento cultural de novo gênero, uma vez que promovem sua imagem através de um universo estético. Nesse contexto, as instituições saem em defesa de grandes causas com o intuito de gerar sentido e valores para engajar seu público. Afinal, a hipercultura revela consumidores que almejam um suplemento que possa ajudá-los na construção de suas identidades - e essas têm sido embasadas em princípios estéticos. Assim, o artigo propõe uma análise desse contexto a partir da marca latino-americana "Flavia Aranha" a fim de verificar as relações entre marca e cultura, tendo em vista a valorização de uma arte que leve em consideração saberes não institucionalizados, contrariando uma noção hegemônica de cultura.
\end{abstract}

Palavras-Chave: arte; cultura popular; hipercultura; saberes tradicionais.

\section{Resumen}

Actualmente, las marcas pueden ser reconocidas como un elemento cultural de nuevo género, una vez que promueven su imagen a través de un universo estético. En este contexto, las instituciones salen en defensa de grandes causas con el propósito de generar sentido y valores para involucrar su público. A fin de cuentas, la hipercultura revela consumidores que desean un suplemento que pueda ayudarles en la construcción de sus identidades - y esas han sido basadas en principios esteticos. Así, el artículo propone un análisis de ese contexto a partir de la marca latinoamericana "Flavia Aranha" a fin de verificar las relaciones entre marca y cultura, con vistas a la valorización de un arte que tenga en cuenta saberes no institucionalizados, contrariando una noción hegemónica de cultura.

Palabras claves: arte; cultura popular; hipercultura; saberes tradicionales.

\begin{abstract}
Currently the marks can be recognized as a new cultural genre, once that they promote your image through an aesthetic universe. In this context, the institutions come out in defense of big issues with the aim of generating meaning and values to engage your audience. After all, the hiperculture reveals consumers who crave a supplement that can help them in building of their identities - and these have been based on aesthetic principles. Thus, the article proposes an analysis of this context from the Latin American brand "Flavia Aranha" to verify the relationship between brand and culture, with a view to the development of an art that takes into consideration non-institutionalized knowledge, contrary to a hegemonic notion of culture.
\end{abstract}

\footnotetext{
${ }^{1}$ Artigo apresentado no Simpósio Temático (RELAÇÕES ÉTNICO-RACIAIS NA AMÉRICA LATINA: DEBATES INTERSECCIONAIS NA DIÁSPORA) durante o II Seminário Latino-Americano de Estudos em Cultura - SEMLACult em Foz do Iguaçu/PR, Brasil, 2018.
}

2 (Mestranda em Arte e Cultura Visual; Universidade Federal de Goiás - UFG; Goiânia, Goiás, Brasil; contatolanagomides@gmail.com) 
Keywords: art; hiperculture; popular culture; traditional knowledge.

\section{Introdução}

É perigoso viajar em busca de história. Se pedirmos ajuda ao primeiro guia desavisado, ele nos entregará um mapa cheio de classificações. Seguir suas instruções parece fácil, afinal, tudo aparenta estar no seu devido lugar: indígenas em suas tribos, os pretos em seus guetos, os camponeses produzindo o alimento que chega a nossa mesa e a indústria produzindo e facilitando o nosso dia a dia. Pode não parecer óbvio, mas essas categorizações estão cheias de armadilhas e são um tanto romantizadas.

Para a jornada não ser tão longa, façamos um recorte nos percursos da cultura popular que tem entrado em contato com a moda hegemônica. Independentemente de qual for esse popular, haverá tensões constantes entre ele e uma cultura dominante que teve seus padrões disseminados graças à história construída pelo olhar eurocêntrico.

A cultura popular não é, num sentido "puro", nem as tradições populares de resistência a esses processos, nem as formas que as sobrepõem. É o terreno sobre o qual as transformações são operadas. Nos estudos da cultura popular, devemos sempre começar por aqui: com o duplo interesse da cultura popular, o duplo movimento de conter e resistir, que inevitavelmente se situa em seu interior (HALL, 2003, p. 248-249).

Pode soar contraditório, mas, para construirmos nossos próprios mapas é necessário desconstruir classificações e visões estereotipadas, tendo em vista que a busca pela compreensão do popular deve ser constante e, por isso, dificilmente se dá por encerrada. A desconstrução acontece através do contato, até porque as interações com os indivíduos de diferentes comunidades são fatores que tendem a nos tirar da zona de conforto ao ampliar nossa visão, que tende a ser limitada.

Assim, por diferentes motivos, pesquisadores, figuras da indústria cultural e consumidores partem em busca do popular e, muitas vezes, seus trânsitos se cruzam. No caso a ser analisado neste artigo temos o encontro de consumidores que buscam, através da moda, construir suas identidades pautadas em princípios (supostamente) éticos e de uma marca Flavia Aranha - que evidencia sua criação a partir da valorização dos conhecimentos tradicionais e técnicas de agricultores, artesãos e costureiras (o popular do qual esta pesquisa aborda) com os quais ela trabalha. Como diriam Gilles Lipovetsky e Jean Serroy, "aqui o comercial se mescla com o cultural, com a arte e a estética" (LIPOVETSKY e SERROY, 2011, p.7). Por isso cabe aqui a análise dessa marca, já que as roupas comercializadas na loja advêm de parcerias entre a estilista e grupos populares que bordam, fiam algodão, se utilizam 
de cascas, folhas e outros elementos naturais para tingir tecidos, entre vários outros hábitos culturais, para criar cores e costuras para as vestimentas.

Essa interação resulta em contribuições significativas para as comunidades? Até que ponto isso pode resultar na perpetuação das produções tidas como tradicionais? Será que a Flavia Aranha atua com uma ideia salvacionista? Essas perguntas não precisam e não devem ser respondidas de imediato. Mas, é importante ter em vista que essas trocas culturais contemporâneas resultam na dissolução de fronteiras "a partir da ruptura de barreiras entre alta cultura e cultura de massa" (RESENDE, 2002, p. 121).

Enquanto Néstor Canclini (1998) e Beatriz Resende (2002) veem essas aproximações a partir de uma perspectiva positiva, há autores do campo da cultura visual que qualificam essas rotas como caminhos um tanto negativos.

Da mesma maneira que se constrói um hipercapitalismo tentacular e globalizado, vemos desenvolver-se o que se pode chamar uma hipercultura, uma cultura-mundo. Ela se define em primeiro lugar pelo fim da separação entre cultura e economia, em segundo lugar pelo significativo desenvolvimento da esfera cultural, em terceiro lugar pela absorção dela pela ordem mercantil. A cultura que caracteriza a época hipomoderna não é mais o conjunto das normas sociais herdadas do passado e da tradição (a cultura no sentido antropológico), nem mesmo o "pequeno mundo" das artes e das letras (a alta cultura); ela se tornou um setor econômico em plena expansão, a tal ponto considerável que se chega a falar, não sem razão, de "capitalismo cultural". (LIPOVETSKY e SERROY, 2011, p. 68).

Claro, há que se tomar o cuidado para não cair na romantização dessas relações, que podem conter níveis de conflitos. No entanto, é possível visualizar certa conquista de espaço por parte do popular. Nesse ponto, Canclini (1998) levanta reflexões acerca das trocas entre o povo e a indústria apontando contribuições significativas da hegemonia para a perpetuação dos artesanatos. Isso não quer dizer que a cultura dos artesãos permanecerá a mesma. Pelo contrário, suas produções se transformam a partir desse contato e sobrevive, derrubando o discurso comum de que a cultura do povo possui o destino fatídico de "cair por terra".

Mas o que já não se pode dizer é que a tendência da modernização é simplesmente provocar o desaparecimento das culturas tradicionais. O problema não se reduz, então, a conservar e resgatar tradições supostamente inalteradas. Trata-se de perguntar como estão se transformando, como interagem com as forças da modernidade. (CANCLINI, 1998, p. 218).

Nesse contexto, como se apresenta essa hipercultura abordada por Lipovetsky e Serroy (2011)? Por que esses consumidores buscam esse contato com os saberes populares através da moda? Caso os agricultores, os artesãos e as costureiras, que trabalham com a Flavia Aranha, não tivessem essa relação com a marca, as pessoas que consomem essa moda sustentável se importariam em saber da existência de seus trabalhos? O presente artigo intenciona se aproximar dessas questões evidenciando essa relação que se desemboca num emaranhado 
constituído por marcas e consumidores sustentáveis e produtores (detentores do saber popular).

\section{Traçando rotas: a viagem começou}

Na sociedade em geral, há muito que o consumo não é feito apenas para o suprimento das necessidades básicas humanas e passou a atuar como uma ferramenta de construção de identidades - não é por acaso que elas têm sido reformuladas, constantemente, sobre princípios estéticos, e não éticos. O contexto da moda é o espaço em que mais se sente o consumo como uma forma de revitalizar o sentido da própria vida. As pessoas se transvestem dos valores (raciais, éticos, a favor do meio ambiente, entre outros) vendidos pelas marcas, sendo que, fazer parte de um nicho que apoia determinada causa pode ser um indicativo de status.

Daí em diante, a marca pretende-se global e cultural, criadora de um universo de vida, de um estilo de vida global. Estamos na época em que criar produtos já não basta: é preciso criar uma identidade ou uma cultura de marca por meio do marketing, do superinvestimento publicitário e da hipertrofia da comunicação [...] Pois o que o hiperconsumidor compra em primeiro lugar é a marca, e com ela um suplemento de alma, de sonho e de identidade. (LIPOVETSKY e SERROY, 2011, p. 95).

Quando a estilista Flavia Aranha começou a planejar seu negócio, ela diz ter tido a percepção de que precisaria construir uma rede de fornecimento que não fosse óbvia ${ }^{3}$. Sua tentativa precisava estar centrada em novas alternativas que apoiassem causas. Há uma exigência de comunicação em que as marcas devem estar atentas a uma procura de novidades e cultura por parte do hiperconsumidor, o que proporciona uma mescla de arte, moda e comercial (LIPOVETSKY e SERROY, 2011). Eis que surge um elemento cultural de novo gênero.

Consequentemente, a moda assume uma de suas funções mais preponderantes: representar o indivíduo que está em busca de sentimento de inclusão em determinada causa ou grupo. Quem opta por vestir Flavia Aranha conhece os valores da marca e assume a identidade de consumidor consciente que, nesse caso em específico, valoriza o processo produtivo entremeado por saberes e tradições fazendo com que as memórias desse povo possam resultar em visibilidade e retorno financeiro. Não sabemos até que ponto a afirmação anterior se confirma e se o capital gerado a essas comunidades são compatíveis ao seu

\footnotetext{
${ }^{3}$ Informação retirada do blog da loja. Disponível em: <http://flaviaaranha.com/new-blog/2017/4/6/nossa-loja-dematria-prima>. Acesso em: 11 jul. 2018.
} 
merecimento ou se está próximo aos ganhos da marca - o que, na maioria dos casos, seria pouco provável por uma série de motivos. A questão que vem ao caso é: será que esse hiperconsumidor ao mesmo tempo em que se simpatiza com a causa não cria fronteiras a partir do momento em que ele precisa de uma marca para fazer essa ponte?

“O popular é nessa história o excluído: aqueles que não têm patrimônio ou não conseguem que ele seja reconhecido e conservado [...] 'incapazes' de ler e olhar a alta cultura porque desconhecem a história dos saberes e estilos" (CANCLINI, 1998, p. 205). Calma! As artesãs do Vale do Urucuia $(\mathrm{MG})^{4}$ sabem muito bem de onde vem a técnica artesanal de tecelagem que costura as roupas dos sujeitos que vestem Flavia Aranha. É certo que Canclini faz essa abordagem para falar da visão construída pelos cânones europeus - e isso não quer dizer que ele concorde com tal posicionamento. Mas, utilizemos esse pensamento hegemônico para provocação: não seria instigante visualizar o consumidor como o viajante incapaz de conhecer a fundo a causa a qual se propõe a "fazer parte"?

Ao mesmo tempo, na tentativa de romper com a ideia de que o popular é resgatado, mas não é conhecido (CANCLINI, 1998), Flavia Aranha afirma entregar um consumo consciente do processo de manufaturação e que valoriza a memória dos produtores, e não somente o produto final. Se for para pensar em categorizações, a marca se classifica nos moldes da moda hegemônica. Afinal, para receber a alcunha de estilista, Flavia Aranha teve que passar pelo sistema acadêmico e, de acordo com os padrões, seu saber é legitimado. Há um senso comum que tende a criar uma separação entre artista e artesão designando o primeiro como um inovador capaz de construir algo único. Já o segundo seria a pessoa que, a partir de métodos tradicionais e manuais, se atém mais ao mero produzir, sem inovação. $\mathrm{O}$ que significa, então, a mescla de trabalhos entre Flavia Aranha e os grupos produtores tradicionais? Para o olhar hegemônico, o produto final desse encontro seria deturpado? Do outro lado, será que hiperconsumidores estão vestindo a causa consciente porque alguém, que possui um lugar de fala tido como dominante, determinou a importância dessa atitude?

"Até mesmo dentro do mesmo período cultural uma mesma obra pode funcionar tanto como arte popular quanto como arte maior, dependendo da maneira que é interpretada e apropriada pelo público" (SHUSTERMAN, 1998, p.100). Engraçado é que a moda "passa", certo? Há quem carregue consigo as causas pelas quais luta pelo resto da vida. Mas não podemos perder de vista aquele hiperconsumidor "sustentável" que se apropria dos ideais para

\footnotetext{
${ }^{4}$ Grupo de artesãs que tem parceria com Flavia Aranha para a produção de peças especiais em xinil. Disponível em: 〈http://flaviaaranha.com/new-blog/2017/7/14/pau-brasil-o-nosso-vermelho〉. Acesso em: 11 jul. 2018.
} 
obter status. Chega um momento em que ele vai "lavar as mãos" e procurar outra "tribo". Esse tipo de contato conseguiu chegar a algum tipo de desconstrução?

Como se dá essa relação entre a marca Flavia Aranha e os grupos produtores? Que tipo de informação sobre os aspectos dessa cultura popular o consumidor tem acesso? Afinal, quais são os benefícios para todos os passageiros que embarcam nessa viagem?

\section{Conhecendo os passageiros}

A Flavia Aranha é uma marca brasileira com loja física na cidade de São Paulo cuja premissa básica é a produção e venda de roupas com design atemporal e tingimento natural.

No menu do site que contém informações sobre a marca, há o seguinte fragmento:

Além de vestir a roupa é também registro de seu processo produtivo, que revela uma trama preciosa de saberes, tradições e improvisos, urdidos na produção artesanal. Ater-se a essa memória é valorizar não só o produto final, como também seus materiais e especialmente, quem o produziu. (ARANHA, 2018. Disponível em: 〈http://flaviaaranha.com/atelie/〉. Acesso em: 10 jul. 2018.).

Adentrando nas postagens do blog não é difícil encontrar registros do contato da marca com diversas figuras da chamada cultura popular. Em relação à figura 1, Flavia Aranha conta sobre a viagem - agora, no sentido literal da palavra - que fez à Unaí (MG) com o intuito de estabelecer contato com a tradição ancestral cultivada pelas artesãs da região. Com o algodão em mãos, essas mulheres fiam, tingem (com folhas, cascas, e raízes do bioma do Cerrado) e finalizam o trabalho com tecelagem artesanal e bordado livre - cujo tema é a cultura local. A coleção de acessórios da marca advém dessa produção.

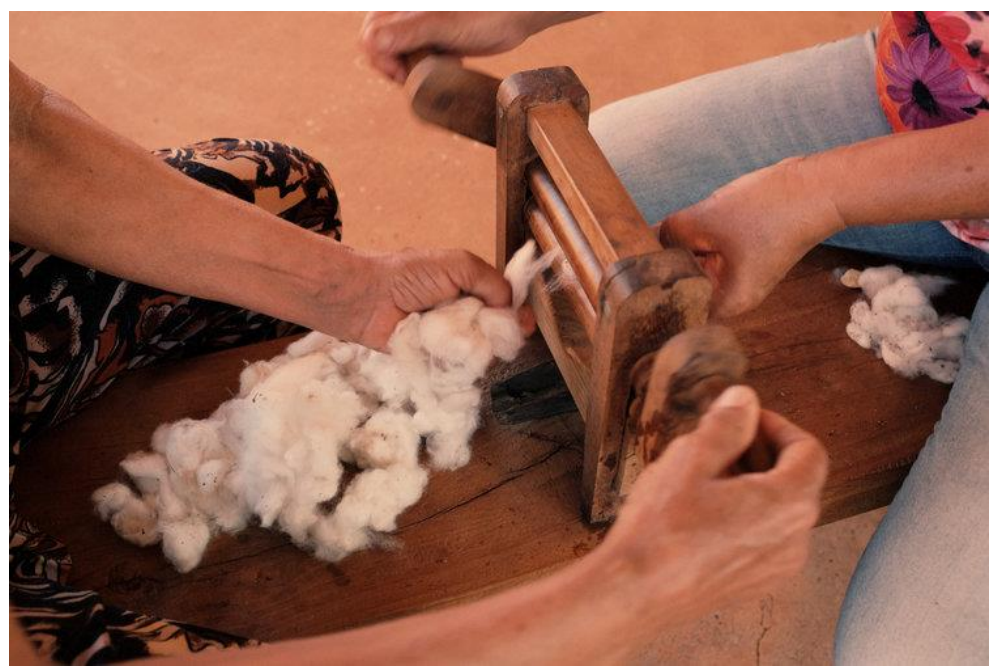

Figura 1 - Produção de tecidos em tear artesanal no Vale do Urucuia

Fonte: Blog Flavia Aranha, 2017 
Vasculhando um pouco mais é possível ver a relação da marca com artesãs da Linha Nove, grupo formado por mulheres pertencentes às comunidades Favela da Linha, Favela do Nove e Cingapura Madeirite. Seus bordados deram início ao Instituto Acaia e juntas elas conseguiram mais autonomia podendo gerar uma complementação para a renda familiar.

Mas, o que mais chama a atenção entre as várias relações listadas no blog é o Projeto Circular - ideia que surgiu com o intuito de repensar o consumo na sociedade atual. As clientes levaram à loja uma peça da marca em bom estado e, assim, tiveram desconto em alguma roupa nova da coleção. Com as peças arrecadadas, Flavia Aranha fez um brechó on-line. Segundo informações do blog, cem por cento da renda gerada foi direcionada a projetos socioambientais que são ligados aos grupos produtores que trabalham com a marca.

Ao passo que Flavia Aranha tem uma iniciativa de retorno a essa cultura popular, a contrapartida por parte dos clientes não parece competir de igual para igual. Nos primeiros três meses de existência do projeto apenas 35 peças foram arrecadadas. Considerando o fato de a loja possuir 25,4 mil seguidores na rede social Instagram, a devolutiva por parte dos consumidores não parece um pouco lenta? Sim, há alguns fatores que podem intervir nesse número - alguns perfis são de concorrentes e outros de pessoas que não compram efetivamente. Ainda assim, convém indagar: será que os seguidores que estão ali só para "olhar" estabelecem algum tipo de contato com o popular que possa fazer com que eles conheçam esse povo de fato? Seria a oportunidade para o consumidor saber da existência desses grupos e ele mesmo estabelecer pontes? Ou ele não se importa porque, afinal, deixar curtidas na página já o deixa com a consciência tranquila?

Inclusive, Flavia Aranha dá oportunidade para as pessoas terem contato com esses saberes que não são institucionalizados ao compartilhar os conhecimentos adquiridos com o povo através de oficinas e workshops em seu ateliê. A figura 2 trata de uma publicação no perfil da loja falando sobre os cursos de Impressão Botânica, Tingimento Natural com ingredientes nativos brasileiros e Tingimento Natural com Pau-Brasil. Isso pode ser considerado uma via de acesso a esses saberes mesmo quando o indivíduo não tem o intuito de se tornar um consumidor da marca. 


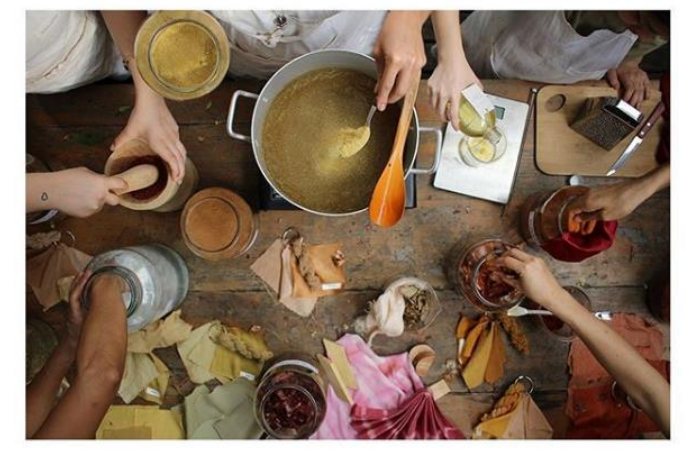

Figura 2 - Post no Instagram para divulgação de cursos

A marca demonstra preocupação acerca do processo de construção de identidades do povo brasileiro, um aspecto que fica mais evidente quando traz em suas roupas o resíduo do Pau-Brasil. Nesse sentido, valoriza a preservação de histórias e memórias que são levadas aos seus consumidores. Na figura 3, por exemplo, tem-se o registro de um trabalho desenvolvido com as bordadeiras do Coletivo Marista. Os vários encontros proporcionados por esse projeto trouxeram a essência do trabalho manual. No blog, foi registrado: "Foram vários encontros em nosso jardim. Tardes de pontos, pespontos, histórias, memórias. Entender o papel do trabalho manual, sob uma perspectiva plural, e nesse caso, pelo bordado, é enriquecedor e inspirador" (ARANHA, 2018).

A bordadeira Lilian menciona sentir falta da permissividade de acesso a grandes marcas ou estilistas nos projetos sociais que lidam com grupos produtivos e que os trabalhos que eles encontram não valorizam a mão de obra artesanal. Já Flavia Aranha parece escapar daquela atitude salvacionista ao estudar e investigar o popular, respeitando e compartilhando suas memórias. 


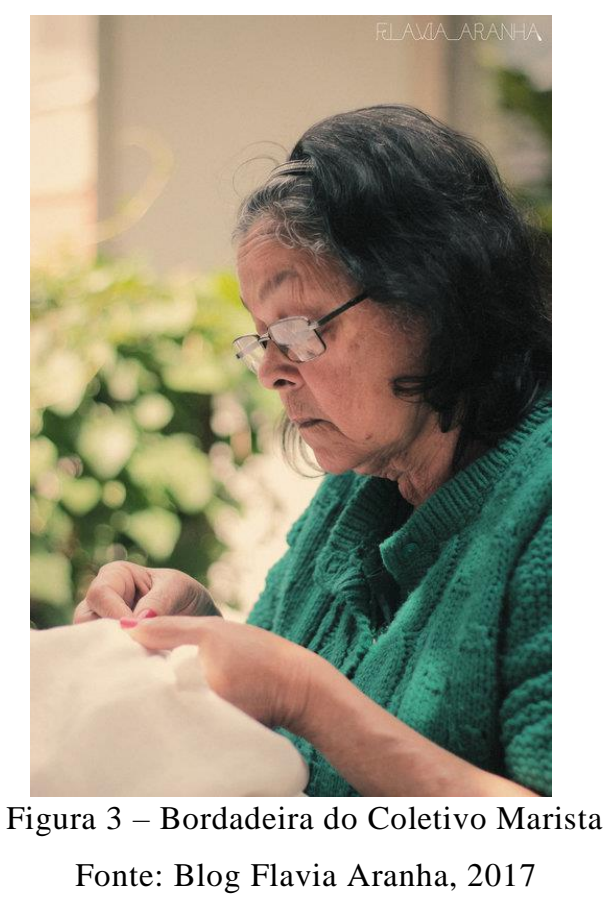

Renato Ortiz em sua obra "Românticos e Folcloristas: cultura popular" aborda que nos séculos 17 e 18 o processo de interação cultural inter-classes não era simétrico, uma vez que a elite participava da tradição do povo, mas este não partilhava de seu universo (ORTIZ, 1992). Com o caso da marca em análise, teríamos uma mudança de perspectiva? Afinal, preocupar-se em definir o que é e o que não se encaixa como "popular", aproveitar a produção desse grupo para embasar um tom nacionalista e fazer com que isso sirva de engrenagem para o desenvolvimento de algo "maior" para a elite sem estudar o artesão de fato, mas, apenas o que ele produz, provavelmente não é o melhor caminho a ser tomado para o estudo da cultura popular. Essas atitudes silenciam e não geram trânsitos pertinentes para nenhum lado, fazendo com que os grupos produtores permaneçam como espectadores de um sistema da arte excludente e os estudos não saiam de uma encenação, como diria Canclini (1998).

Ao que parece, Flavia Aranha intenciona andar lado a lado com cultura popular, sendo que as comunidades têm uma contrapartida financeira e de valorização de suas memórias e tradições. Quanto aos consumidores, fica a critério deles um aprofundamento nessas relações. Talvez, sua maior contribuição possa ser o fato de optar por essa moda em detrimento de outras marcas que não se prestam a esse tipo de trabalho social. Mas, é provável que nem todos os clientes busquem a marca defendendo uma causa sustentável, 
e sim um estilo que lhe pareça esteticamente prazeroso já que advém de uma estilista com certo renome.

Como já foi dito, nem tudo pode ser romantizado.

\section{Conclusões}

Como diria Ortiz, são os intelectuais que definem a legitimidade do que seria, ou não, popular na maioria das vezes (ORTIZ, 1992). Não poderia me despedir desse trecho da viagem sem deixar claro que, querendo ou não, faço parte do sistema acadêmico de ensino no campo da cultura visual, o que com certeza influencia minha visão sobre o assunto. Do meu lugar de fala, acabo determinando os grupos compostos por agricultores, artesãos e costureiras como populares. Reconheço que algumas categorizações foram necessárias para estabelecer a comunicação aqui empreendida. Mas, a viagem no estudo da cultura popular não encerra aqui e ainda tomarei diferentes rotas.

Contudo, neste breve passeio, pode-se dizer que há uma tentativa, em meio ao caos do consumismo, de estabelecer conexões válidas com o povo que mantém seus saberes, tradições e memórias arraigados em seus afazeres. Ainda que não seja possível concluir se há conflitos entre a marca Flavia Aranha e seus parceiros produtores, é possível perceber uma devolutiva de sua parte para as comunidades com as quais ela trabalha, seja no quesito de visibilidade ou econômica. Também, a memória coletiva é transmitida, o que é crucial para a resistência de um povo (WALSH, 2013).

Claro, ainda há o que ser feito. Por que não há o incentivo de contato real entre os populares e seus clientes (algo que vá além dos relatos no blog)? Clientes que, aliás, saem de viagem sem revisar as condições do veículo. Há interesse na causa, mas, o contato direto não é evidenciado - não houve nenhum comentário, por parte dos consumidores, durante as pesquisas para a escrita deste trabalho que demonstrasse interesse numa aproximação com os grupos que vá além dos cursos oferecidos pela própria Flavia Aranha. Mas, quem sabe isso seja encontrado numa próxima excursão?

\section{Referências}

Blog Flavia Aranha. Disponível em: https://www.flaviaaranha.com/. Acesso em: 20 julho 2018.

CANCLINI, Néstor García. Culturas Híbridas - estratégias para entrar e sair da modernidade. São Paulo: EDUSP, 1998. (Obra completa) 
HALL, Stuart. Notas sobre a desconstrução do popular. In: HALL, Stuart. Da diáspora Identidades e Mediações Culturais. Belo Horizonte: Editora UFMG, 2003, p. 247- 264. (Capítulo de livro)

Instagram Perfil Flavia Aranha em: https://www.instagram.com/flaviaaranha/?hl=pt-br. Acesso em: 20 julho 2018.

LIPOVETSKY, Gilles e SERROY, Jean. A cultura-mundo, respostas a uma sociedade desorientada. São Paulo: Companhia das Letras, 2011. (Obra completa)

ORTIZ, Renato. Românticos e Folcloristas: cultura popular. São Paulo: Editora Olho d'Água, 1992. (Obra completa)

RESENDE, Beatriz. Ruídos da música popular. In: RESENDE, Beatriz. Apontamentos de crítica cultural. Rio de Janeiro: Aeroplano Editora e Fundação Biblioteca Nacional, 2002, p. 121-169. (Capítulo de livro)

SHUSTERMAN, Richard. Vivendo a arte: o pensamento pragmatista e a estética popular. São Paulo: Editora 34, 1998. (Obra completa)

WALSH, Catherine. Pedagogías decoloniales: Prácticas insurgentes de resistir, (re)exisir y (re)vivir. TOMO I. Quito, Ecuador: Ediciones Abya-Yala, 2013. (Obra completa) 